Article

\title{
Ang Pilosopiya ni Pierre Bourdieu bilang Batayang Teoretikal sa Araling Pilipino
}

\section{F.P.A. Demeterio III and Leslie Anne L. Liwanag}

\begin{abstract}
This paper is basically a presentation of the tenets of Pierre Bourdieu's philosophy in a language and level that can be easily understood by Filipino students and scholars of philosophy, cultural studies and Philippine studies. The discussion of Bourdieu's philosophy revolves around 1) his concepts of habitus, field and symbolic violence; 2 ) his critique of television; 3 ) his theory of capitals; 4) some implications of his theory of capitals; and 5) his being public intellectual. The ultimate aim of this paper is to suggest some aspects and dimensions of Philippine society and culture that can be analyzed using some of bourdieu's thoughts as interpretive frameworks, as well as to challenge the said Filipino students and scholars of philosophy, cultural studies and Philippine studies to creatively and effectively appropriate such theories for the enrichment of the theoretical corpus of Philippine studies. This paper is part of a series of similar works done by one of the co-authors that dealt with Adorno, Schleiermacher and Dilthey, Heidegger, Gadamer and Bultmann, and Lyotard.
\end{abstract}

Keywords: Bourdieu, Philippine Studies, habitus, social reproduction

\section{Introduksiyon}

$\mathrm{H}$

angarin ng papel na itong mailahad ang mga mahalagang aspekto ng kaisipan ni Pierre Bourdieu (1930-2002). Isa siyang Pranses na sosyolohista, antropolohista, pilosopo, at aktibistang lumalaban sa globalisasyon. Hindi lamang iinog ang papel sa wikang Filipino, bagkus ipapamalas ang antas ng diskursong maiintindihan ng mga kapwa Pilipinong nasa larangan ng araling kultural at araling Pilipino. Makatutulong ito sa mga wala pa masyadong kasanayan sa antas ng diskursong pilosopikal, sa mga Pilipinong mag-aaral ng pilosopiyang marahil hindi pa handang basahin ang mga primaryong teksto ni Bourdieu o ang mga komplikadong babasahin tungkol sa kanya na naisulat na sa wikang Ingles. 


\section{ANG PILOSOPIYA NI PIERRE BOURDIEU}

Tunguhin din ng papel na itong matukoy ang ilang aspekto mula sa naturang banyagang diskurso para lalong mapagyaman ang teoretikal na kalipunan ng lokal na araling kultural at araling Pilipino.

Ipinanganak si Bourdieu sa isang rural na rehiyon ng Bearn na matatagpuan sa paanan ng kabundukang Pyrenees, sa timog-kanlurang bahagi ng Pransiya. Napabibilang siya sa angkan ng mga ingkilino at maliliit na kawani ng gobyerno. Nag-aral siya ng elementarya at sekondarya sa karatig na bayan kasama ang mga anak ng mga magsasaka, manggagawa, at may maliliit na negosyo. Sa pamamagitan ng kanyang angking talino at sipag, nabiyayaan siya ng iskolarship ng gobyerno at nakapag-aral sa Lycee Louis-le-Grand. Dito pinaghandaan niya ang kanyang pagpasok sa prestihiyosong Ecole Normale Superieure. Sa Ecole Normale Superieure, ang resulta ng kanyang entrance examination ang naglagay sa kanya sa programang pilosopiyang tinagurian noong reyna ng mga siyensiya. Kaya naging guro niya ang mga batikang pilosopong katulad nina Louis Althusser (1918-1990), Alexandre Koyre (1892 -1964), Gaston Bachelard (1884-1962) at Georges Canguilhem (1904-1995). Gawa rin ng kanyang pagkalagay sa programang pilosopiya, napasama siya sa intelektuwal na pakikipaglaban sa hegemonya ng eksistensiyalismo ni Jean Paul Sartre (1905-1980).

Matapos niyang makamtan ang degri kasabay ang pilosopo at kritikong si Jacques Derrida (1930-2004), minabuti ni Bourdieu na magturo ng pilosopiya sa isang maliit na bayan ng Moulins sa kalagitnaang bahagi ng Pransiya. Inaasahan ng maraming kalaunan sasama si Bourdieu sa elitistang lupon ng mga pilosopong Pranses, ngunit tinahak niya ang hindi ganoong kaglamorosong disiplina ng sosyolohiya.

Noong 1955, kinailangan niyang magbigay-serbisyo militar. Gawa ng kanyang taglay na pagkarebelde, ipinadala siya sa Algeria na kolonya pa ng Pransiya. Nagkaroon ng malalim na epekto sa paghugis ng kanyang kaisipan ang karanasan niya sa Algeria, dito nasaksihan niya ang nasyonalistang pakikipaglaban ng mga Algeriyano.

Bunsod nito, tuluyan niyang iniwan ang landas ng pilosopiya at sa halip tumuon sa mga praktikal at kongkretong paksa ng sosyolohiya. Nakilala siya ng mga sosyolohistang Pranses dahil sa kanyang kauna-unahan etnograpikong proyekto tungkol sa mga Berber.

Gawa ng kanyang sentimiyento laban sa digmaan at kolonyalismo, minabuti ng pamahalaang Pranses na alisin siya sa Algeria at pabalikin na lamang sa Pransiya.

Sa pamamagitan nito, nakapagturo at nakapanaliksik si Bourdieu sa University of Paris at sa Ecoles des Hautes Etudes en Sciences Sociales. Dito nakatrabaho niya ang batikang sosyolohistang si Raymond Aron (1905-1983) at itinayo niya ang Centre for the Sociology of Education and Culture.

(c) 2014 F.P.A. Demeterio III and Leslie Anne L. Liwanag http://www.kritike.org/journal/issue 15/demeterio\&liwanag december2014.pdf ISSN 1908-7330

(cc) $\mathrm{BY}-\mathrm{NC}$ 
Sa paglipas ng panahon iginawad sa kanya ang professorial chair ng sosyolohiya sa College de France at ang prestihiyosong Gintong Medalya mula sa Centre National de Recherche Scientifique. Sumakabilang buhay siya noong 2002 dahil sa sakit na kanser.

Nakapaglathala si Bourdieu ng mahigit apatnapung libro at limangdaang artikulo. Ilan sa kanyang mga pangunahing libro ang Reproduction in Education, Society and Culture (1970) na isinulat kasama si JeanClaude Passeron; ang Outline of a Theory of Practice (1972); Distinction: a Social Critique of the Judgment of Taste (1984); Homo Academicus (1984); In Other Words: Essays towards Reflexive Sociology (1987); Practical Reason: on the Theory of Action (1998); Language and Symbolic Power (1991); at On Television (1999). Bukod sa larangan ng sosyolohiya at pilosopiya kinilala din ang kanyang mga naging intelektuwal na ambag sa panitikan, sining, edukasyon, araling kultural, araling mas midya, at araling post-kolonyal.

Tatalakayin ng papel na ito ang kaisipan ni Bourdieu sa ilalim ng apat sub-seksiyon na tungkol sa kanyang: 1) mga konsepto ng habitus, larangan at simbolikong dahas; 2) pagsusuri sa telebisyon; 3) teorya ng mga kapital; 4) ilang implikasyon ng teorya ng mga kapital; at 5) pagiging isang pampublikong intelektuwal.

\section{Habitus, Larangan at Simbolikong Dahas}

Isa sa mga pangunahing pakay ni Bourdieu ang pagsaliksik sa kultural na pagkakaiba ng mga panlipunang uri. Sinuri niya ang kung ano ang ugat ng pagkakaibang ito, paano pinapanatili ng ganitong pagkakaiba ang inhustisya at kawalan ng pagkakapantay-pantay sa lipunan, at paano isinasalin ng isang panlipunang uri ang kanyang partikular na kultura mula sa isang henerasyon patungo sa kasunod na henerasyon. Para matugunan ang ganitong mga katanungan ginamit niya ang mga konseptong habitus, larangan (field), at simbolikong dahas (symbolic violence).

Hinango niya ang ideya ng habitus mula sa kaisipan ni Aristotle (384$322 \mathrm{BCE})$, sa mga Eskolastiko, at sa ilang mga modernong sosyolohista katulad nina Marcel Mauss (1872-1950), Nobert Elias (1897-1990), at Max Weber (1864-1920). Ginamit niya ang habitus bilang solusyon sa teoretikal na problema tungkol sa kung alin ang mas mahalaga, ang indibidwal ba o ang sistema at estruktura. Ayon sa kanya, ang habitus ay isang:

System of durable, transposable dispositions, structured structures predisposed to function as structuring structures, that is, as principles which generate and organize practices and representations that can be objectively adapted to their outcomes without

(C) 2014 F.P.A. Demeterio III and Leslie Anne L. Liwanag

http://www.kritike.org/journal/issue 15/demeterio\&liwanag december2014.pdf

ISSN 1908-7330 


\section{ANG PILOSOPIYA NI PIERRE BOURDIEU}

presupposing a conscious aiming at ends or an express mastery of the operations necessary in order to attain them."1

Ibig sabihin, isang sistema ng disposiyon sa pagkilos, pakiramdam, at pag-iisip ang habitus, at ito ay hinubog ng obhektibong estruktura ng kanyang kongkretong kondisyon. ${ }^{2}$

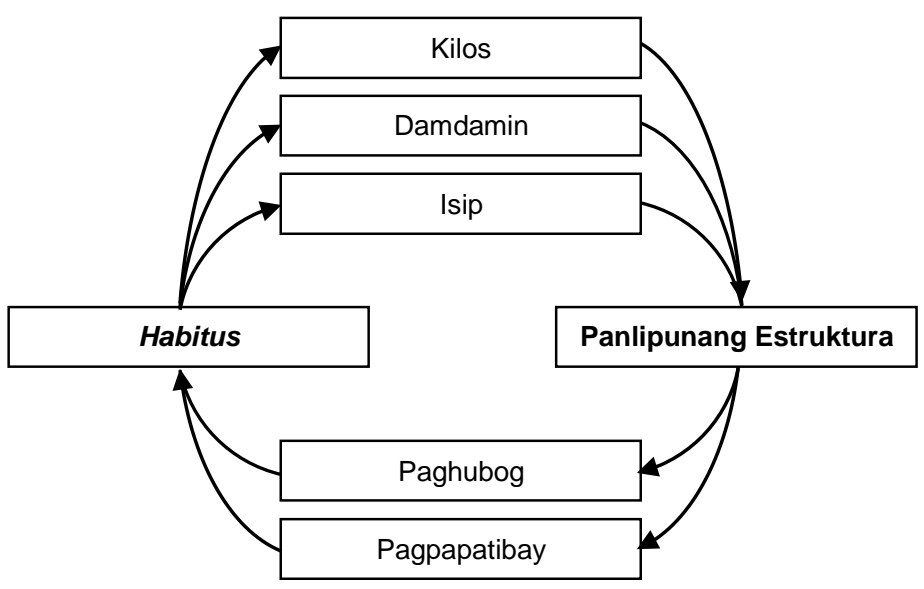

Figure 1: Ugnayan ng Habitus at Panlipunang Estruktura

Nagmumula sa habitus ang bawat kilos, damdamin, at isip ng isang indibidwal na tumutulong sa paglikha ng mga obhektibong panlipunang estruktura. Habang hinuhubog at pinapatibay ng habitus ang mga panlipunang estruktura, masasabing maaaring mamana rin ang habitus ng isang indibidwal mula sa kanyang kinalakihang tahanan at kapaligiran. ${ }^{3}$

Ilan sa mga terminong ginamit ni Bourdieu para lalong maipaliwanag ang konsepto ng habitus ang "cultural unconscious," "habitforming force," "set of basic, deeply interiorized master-patterns," "mental habit," "mental and corporeal schemata of perceptions, appreciations and actions," at "generative principle of regulated improvisations." ${ }^{4}$

Hindi siya sang-ayon sa deterministikong kaisipan na ang sistema at estruktura ang humuhubog sa kilos, damdamin, at isip ng isang indibidwal. Gayundin sa rasyonalistikong kaisipan na ang kilos, damdamin, at isip ng isang indibidwal na malayang-malaya sa hegemonya ng sistema at estruktura.

${ }^{1}$ Pierre Bourdieu, The Logic of Practice, trans. by Richard Nice (California: Stanford University Press, 1990), 53.

2 See ibid., 55; see Figure 1.

${ }^{3}$ See Figure 1.

${ }^{4}$ Bourdieu, The Logic of Pratice, 52-56.

(C) 2014 F.P.A. Demeterio III and Leslie Anne L. Liwanag http://www.kritike.org/journal/issue 15/demeterio\&liwanag december2014.pdf ISSN 1908-7330 
Ito ang dahilan kung bakit ginamit niya ang habitus bilang tulay sa pagitan ng magkatunggaling determinismo at rasyonalismo. Maaaring bigyan ng habitus ng sapat at parehong kahalagahan ang indibidwal at ang sistema, o estruktura. Dagdag niya:

The habitus contains the solution to the paradox of objective meaning without subjective intentions. It is the source of the strongs of 'moves' which are objectively organized as strategies without being the product of a genuine strategic intention-which would presuppose at least that they be apprehended as one among other possible strategies. ${ }^{5}$

Kapag ituturing ang habitus bilang kultura ng isang panlipunang uri o ng isang maliit na pangkat ng isang panlipunang uri, akmang-akma ang kulturang ito sa estruktura at kondisyon ng naturang uri o pangkat dahil hinubog ito sa puwersa ng parehong estruktura at kondisyon.

Tinatawag na habitus ang pagsasaloob ng indibidwal sa mga estruktura at kondisyon ng kanyang kalagayan at kapaligiran. Ito ang dahilan kung bakit kadalasan walang kakayahang mangarap at magplano nang matayog ang isang taong mahirap sapagkat ramdam niya kung ano lamang ang mga abot-kayang posibilidad na maaasahan niya sa kanyang mahirap na kalagayan at kapaligiran. Ang habitus din ang dahilan kung bakit magkakaiba ang kultura ng mga naghaharing uri at inaaping uri, pati na kung bakit iba ang kultura ng isang indibidwal na biglang yumaman at kultura ng mga dati nang mayaman.

Ginamit ni Bourdieu ang konsepto ng larangan bilang pampalit sa makitid na konsepto ni Karl Marx (1818-1883) tungkol sa antagonismo sa gitna ng mga panlipunang uri. Sinang-ayunan ni Bourdieu si Weber na una nang nagsabing mahirap pag-aralan ang isang lipunan kapag ang titingnan lamang ang tunggalian ng mga panlipunang uri. Kung nakatuon si Marx sa antagonismong nakapaloob sa malawak na lipunan, minarapat ni Bourdieu na tingnan ang mas espesipikong antagonismo, o tagisan ng galing $\mathrm{o}$ paligsahang nakapaloob sa mas maliliit na parte ng lipunan.

Kung sinuri ni Marx ang makroskopikong lipunan, sa mikroskopikong larangan nakatutok si Bourdieu. Para kay Bourdieu, isang espasyo sa loob ng lipunan ang larangan kung saan dumidiskarte at nakipagpaligsahan para makamtan ang mga kanais-nais na hangarin ang mga tao at institusyon.

Ipinaliwanag niya at ng kanyang kolaborador na si Loic Wacquant:

${ }^{5}$ Ibid., 62.

(C) 2014 F.P.A. Demeterio III and Leslie Anne L. Liwanag http://www.kritike.org/journal/issue 15/demeterio\&liwanag december2014.pdf

ISSN 1908-7330 


\section{ANG PILOSOPIYA NI PIERRE BOURDIEU}

In a field, agents and institutions constantly struggle, according to the regularities and the rules constitutive of this space of play ... with various degrees of strength and therefore diverse probabilities of success, to appropriate the specific products at stake in the game. ${ }^{6}$

May estruktura ang larangan dahil may mga batas ito kung paano dapat kikilos ang mga nasa loob. Gayundin may kani-kaniyang taglay na kapangyarihan ang bawat nasa loob nito. Isinulat nina Bourdieu at Wacquant:

... the field as a structure of objective relations between positions of force undergirds and guides the strategies whereby occupants of these positions seek, individually or collectively, to safeguard or improve their position and to impose principles of hierarchization most favorable to their own products. ${ }^{7}$

Isang halimbawa ng larangan ang mundo ng akademiya kung saan nagtatagisan ng galing sa pagtuturo, pagsasaliksik at paglilimbag ang mga propesor. Isang pa ang mundo ng mga mag-aaral kung saan nagtatagisan din ang mga ito sa pag-aaral at paglilinang sa kani-kanilang sarili bilang mga umuusbong na pinuno at eksperto sa iba't ibang kurikular at ekstra-kurikular na gawain.

Maituturing ding mga larangan maging ang relihiyon, siyensiya, o ang ano pa mang propesyon kung saan may kani-kanilang batas sa pagdidiskarte at batayan kung ano ang kapangyarihang taglay ng mga nasa loob ng mga ito.

Ayon kay Bourdieu may tatlong uri ng pagdidiskarte para makamtan ang pinakamakapangyarihang posisyon sa loob ng isang larangan: 1) ang konserbasyon ng kapangyarihan para mapanatili ito ng isang indibidwal o institusyon; 2) ang pag-angkin, o pagmana ng kapangyarihan para maisalin ito mula sa unang may hawak patungo sa bagong hahawak nito; at 3) ang subersiyon ng kapangyarihan para mawalan ng lehitimasyon ang unang may hawak nito, o para mapawalang bisa ang naunang kapangyarihan sa pamamagitan ng hindi pagkilala nito bilang isang katanggap-tanggap na anyo ng kapangyarihan. ${ }^{8}$

${ }^{6}$ Pierre Bourdieu and Loic Wacquant, An Invitation to Reflexive Sociology (Chicago: University of Chicago Press, 1992), 102.

${ }^{7}$ Ibid., 101.

${ }^{8}$ See ibid., 102.

(c) 2014 F.P.A. Demeterio III and Leslie Anne L. Liwanag http://www.kritike.org/journal/issue 15/demeterio\&liwanag december2014.pdf ISSN 1908-7330 
Sa pamamagitan ng larangan, ipinakita ni Bourdieu na hindi lamang matatagpuan ang Marxistang konsepto ng antagonismo sa makroskopikong tunggalian ng mga panlipunang uri. Para sa kanya, may taglay na mikroskopikong antagonismo o tagisan ng galing - lantaran man o palihim.

Bilang isang Neo-Marxista, naniniwala si Bourdieu na may taglay ring inhustisya at hindi pagkakapantay-pantay ang lipunan.

Sa pananaw ni Marx, ideolohiya ang itinuturong dahilan sa hindi paglaban ng mga inapi sa mga naghaharing uri at sa pagtanggap ng mga inaapi sa kanilang dehadong kalagayan. Ideolohiya ang bumubulag sa mga inaapi para hindi nila makita ang laganap na inhustisya at hindi pagkakapantay-pantay sa loob ng lipunan. Sa pananaw ng Italyanong Marxistang si Antonio Gramsci (1891-1937), hegemoniya ang sagot sa kaparehong katanungang tumutukoy sa kultura at sistema ng pagpapahalaga ng mga naghaharing uri na kusang tinanggap ng mga inaapi.

Kaakibat ng pagtanggap sa mapang-aping estruktura ng lipunan ang malawakang pagtanggap sa kultura at sistema ng pagpapahalaga ng mga naghaharing uri.

Sa pananaw ni Althusser, repressive state apparatus at ideological state apparatus naman ang sagot sa kaparehong katanungan. Gumagamit ng dahas at banta ng dahas ang repressive state apparatus sa pagpapatupad sa ideolohiya ng mga naghaharing uri, habang banayad na sumusuyo ang ideological state apparatus sa mga tao para tanggapin ang parehong ideolohiya.

Nakaugat sa mahabang tradisyon ng Marxismo ang konsepto ng simbolikong dahas ni Bourdieu. Pumapatungkol ang simbolikong dahas sa estruktural na pagpataw ng mga kategorya ng pag-iisip at pagtingin sa mga indibidwal para tanggapin na lamang nila ang mapang-aping kaayusan ng lipunan.

Nilinaw ni Bourdieu: "Symbolic power is that invisible power which can be exercised only with the complicity of those who do not want to know that they are subject to it or even that they themselves exercise it." ${ }^{\prime 9}$ Kapag tinanggap na ng mga indibidwal ang kasalukuyang kaayusan bilang normal at natural na kaayusan, hindi na nila maisipang punahin ito bilang isang mapang-aping kaayusan o kaya hindi na nila bibigyang oras na pagtangkaang palitan ng mas makatao at mas makatarungang kaayusan.

Ibig sabihin, ginagawang lehitimo ng simbolikong dahas ang kabuoang sistema at estruktura ng lipunan. Katulad sa hegemoniya ni Gramsci at sa ideological state apparatus ni Althusser, isang banayad na pagpilit sa mga indibidwal na sundin na lamang ang kasalukuyang kaayusan

${ }_{9}^{9}$ Pierre Bourdieu, Language and Symbolic Power (Boston: Harvard University Press, 1991), 164.

(C) 2014 F.P.A. Demeterio III and Leslie Anne L. Liwanag http://www.kritike.org/journal/issue 15/demeterio\&liwanag december2014.pdf ISSN 1908-7330 


\section{ANG PILOSOPIYA NI PIERRE BOURDIEU}

at huwag na itong punahin at palitan ang konsepto ng simbolikong dahas ni Bourdieu

Lalong lilinaw ang mga konsepto ng habitus, larangan, at simbolikong dahas kapag tatalakayin na ng papel ang teorya ng mga kapital ni Bourdieu. Bago pa man dumako ang papel na ito sa nasabing teorya, ipapakita muna kung paano ginamit ni Bourdieu ang mga naturang konsepto sa kanyang pagsuri sa telebisyon.

\section{Pagsusuri sa Telebisyon}

Hindi sa aspektong pagbibigay ng libangan nakatuon ang pagsusuri ni Bourdieu, datapwat nakapokus sa pagbabalita at pagbibigay ng impormasyon sa telebisyon. Dagdag dito, nakasentro ang kanyang pagsuri sa katotohanang dapat batayan ng pagbabalita at pagbibigay ng impormasyon. Sa kabila ito ng pagiging mas kilala ni Bourdieu sa larangan ng araling kultural bilang dalubhasa sa pag-uunawa sa libangang dala ng telebisyon gamit ang kanyang teorya ng mga kapital.

Kaya mahalagang linawin na ang Bourdieu'ng mababasa sa librong On Television ang tatalakayin sa seksiyong ito at hindi muna ang Bourdieu'ng mababasa sa librong Distinction na tatalakayin naman sa kasunod na seksiyon.

Hihimayin ng seksiyong ito ang tatlong mahahalagang paksa ng librong On Television: 1) ang tunggalian sa loob ng larangan ng dyornalismong pantelebisyon, 2) ang pagiging sakop ng larangan ng dyornalismong pantelebisyon sa larangan ng ekonomiya at politika, at 3) ang simbolikong dahas na ipinapalaganap ng telebisyon.

Kung babalikan, espasyo sa loob ng lipunan ang larangan kung saan nakikipagtagisan ng galing at dumidiskarte para makamtan ang mga kanaisnais na bagay ang mga indibidwal at institusyon. Alinsunod dito, madaling ituring na isang larangan ang dyornalismong pantelebisyon dahil nagtatagisan din ng galing at dumidiskarte para makikilala bilang isang mahusay na dyornalista ang mga dyornalistang nasa loob ng industriyang ito. Bukod dito, malinaw na nagtatagisan ng galing at dumidiskarte para mahatak ang pinakamaraming manonood ang mga pinagtatrabahuhan nilang himpilan.

Naniniwala si Bourdieu na may malaking epekto sa katotohanan at kalidad ng serbisyong inihahatid ng telebisyon ang tunggalian sa loob ng larangan ng dyornalismong pantelebisyon.

Una, gawa ng pagsisikap ng isang dyornalistang mananatili sa kanyang trabaho at makikilala bilang isang mahusay na mamamahayag, mapipilitan siyang sumunod sa mga nakasulat at hindi nakasulat na patakaran ng kanyang propesyon.

(c) 2014 F.P.A. Demeterio III and Leslie Anne L. Liwanag http://www.kritike.org/journal/issue 15/demeterio\&liwanag december2014.pdf ISSN 1908-7330 
Isa sa mga mahalagang hindi nakasulat na patakaran ang tungkol sa ano dapat at hindi dapat iulat.

Tinawag ito ni Bourdieu na "self censorship" na bunsod sa reyalidad na ang katotohanang inihain ng telebisyon ang isang katotohanang sinala na ng politika sa loob ng propesyong dyornalismo. Winika ni Bourdieu:

It is ... true that at at time such as today, when great numbers of people are looking for work and there is so little job security in television and radio, there is a greater tendency toward political conformity. Consciously or unconsciously, people censor themselves - they do not need to be called into line. ${ }^{10}$

Pangalawa, sa pamamagitan ng tunggalian sa pagitan ng mga himpilan para makuha ang pinakamaraming manonood, minamanmanan ng bawat himpilan ang mga programa at gawain ng kani-kanilang kakompetensyang himpilan na nagreresulta ng pare-parehong programa at gawain sa kabuoan. Nilinaw ni Bourdieu:

People are ready to do almost anything to be the first to see and present something. The result is that everyone copies each other in the attempt to get ahead; everyone ends up doing the same thing. The search for exclusivity, which elsewhere leads to originality and singularity, here yields uniformity and banality. ${ }^{11}$

Kaya hindi napupunan ng ibang himpilan ang kakulangan sa katotohanan ng isang himpilan.

Minsan nasasakop ang isang larangan ng isa pang mas malaki at mas makapangyarihang larangan. Ito ang nangyari sa dyornalismong pantelebisyon, sa puntong pagmamay-ari ng malalaking kompanya ang himpilang ginagalawan nito, o hindi kaya ng gobyerno. May epekto sa katotohanan at kalidad ng serbisyong inihain ng telebisyon ang pagiging sakop ng larangan ng dyornalistang pantelebisyon ng malalaking kompanya o gobyerno. ${ }^{12}$

Una, nagdadagdag ng self-censorship sa mga dyornalista na hindi na maaaring magpahayag ng anomang impormasyon na makakasama sa mayari ng himpilan. Kadalasan, ang mga kompanya na nagmamay-ari ng isang

${ }^{10}$ Pierre Bourdieu, On Television, trans. by Priscella Parkhurst (New York: The New Press, 1998), 15.

${ }^{11}$ Ibid., 20.

${ }^{12}$ See ibid., 16.

(c) 2014 F.P.A. Demeterio III and Leslie Anne L. Liwanag http://www.kritike.org/journal/issue 15/demeterio\&liwanag december2014.pdf

ISSN 1908-7330 


\section{ANG PILOSOPIYA NI PIERRE BOURDIEU}

himpilan ay may-ari din ng marami pang kompanya na hindi rin maaaring ipahamak ng anomang negatibong pahayag. Kapag nagkataong gobyerno ang nagmamay-ari ng isang himpilan, lalong lalawak pa ang self-censorship na ito bunsod sa lawak ng estruktura ng pamahalaan na dapat isa-alangalang ng mga dyornalista.

Pangalawa, dahil sakop ang dyornalismong pantelebisyon ng mas malawak at mas makapangyarihan larangan ng ekonomiya, hinuhugis ng ekonomiya ang anyo at nilalaman ng dyornalismong pantelebisyon. Kundi man aabot sa ilang milyong piso, libo-libo ang halaga ng bawat segundo ng produksyong pantelebisyon. Inihain ang produksiyong ito sa nakararaming indibidwal na abala sa kani-kanilang mga gawain, kaya sadyang mabilis ang takbo ng programang pantelebisyon.

Bunsod sa bilis na ito, naaangkop sa telebison ang mga nilalamang nakamamangha, sensasyonal, at dramatiko, o hindi kaya ang mga nilalamang gasgas, pangkaraniwan, at alam na ng nakararaming manonood. Binigyang-diin ni Bourdieu na: "Time, on television, is an extremely rare commodity. When you use us precious time to say banal things, to the extent that they cover up precious things, these banalities become in fact very important."13 Naniniwala si Bourdieu na hindi uubra ang telebisyon sa paghahain ng mga seryoso, pinag-iiisapan nang mabuti, at hinihimay nang mabuting mga isyu at usapin.

Kaakibat ng telebisyon ang pagsala at pagbaluktot sa katotohanan. Gawa ng kahusayan sa pagtatago at laganap ang pagtanggap ng mga tao nito, malinaw para kay Bourdieu na may taglay na simbolikong dahas ang telebisyon. Una, ipinataw ng mga dyornalista ang kanilang pananaw sa nakararaming manonood. Sa pagtanggap ng mga manonood sa pananaw ng mga dyornalista bilang natural na pananaw, nararanasan nila ang simbolikong dahas. Dagdag pa ni Bourdieu: "They show things and make people believe in what they show. This power to show is also a power to mobilize. It can give a life to ideas or images, but also to groups."14 Pangalawa, ang mga dyornalista at himpilan ang nagpapasya kung ano ang maaari at hindi maaaring ipalabas sa telebisyon, kontrolado nila ang pagsali ng mga indibidwal sa public sphere, o ang espasyo kung saan malaya sanang talakayin ng mga mamamayan ang samu't saring usaping panlipunan. Hawak ng telebisyon kung ano lang dapat ang tatalakayin, at kung paano dapat tatalakayin ang mga usaping nasa sa loob ng public sphere, nararanasan din ng public sphere, mga indibidwal, lipunan, at pati na ng demokrasya ang simbolikong dahas.

\footnotetext{
${ }^{13}$ Ibid., 18.
}

${ }^{14} \mathrm{Ibid} ., 21$.

(c) 2014 F.P.A. Demeterio III and Leslie Anne L. Liwanag http://www.kritike.org/journal/issue 15/demeterio\&liwanag december2014.pdf ISSN 1908-7330 
Pangatlo, kontrolado rin ng mga dyornalista at himpilan ang pagsali ng mga intelektuwal sa public sphere.

Sa mga talakayang pantelebisyon, ang mga dyornalista at himpilan ang pumipili kung sino-sinong mga eksperto at dalubhasa ang dapat nilang yayain sa studio at makapanayam sa harap ng kamera. Kadalasan, pinipili nila ang mga eksperto at dalubhasang kapareho nila ang takbo ng isip, bukod sa kakayahan ng mga ito na mag-isip at magsalita nang mabilis. Inilatag niya:

If television rewards a certain number of fast-thinkers who offer cultural 'fast food'-predigested and prethought culture-it is not only because those who speak regularly on television are virtually on call... The list of commentators varies little. ... These 'authorities' spare journalists the trouble of looking for people who really have something to say, in most cases younger, still-unknown people who are involved in their research and not much for talking to the media. ${ }^{15}$

Para kay Bourdieu, lumalabas na lumilikha ang telebisyon ng mga eksperto at dalubhasa na hindi naman talaga eksperto at dalubhasa sa mata ng kani-kanilang mga kasamahan sa loob ng kani-kanilang disiplina. Dahilan ang patakaran ng telebisyon sa pagpili ng mga eksperto at dalubhasa na hindi tumutugma sa patakaran ng pagkikilala kung sino ba talaga ang mga tunay na eksperto at dalubhasa sa loob ng isang disiplina.

Bilang halimbawa, silang mga indibidwal na bihasa sa sosyolohiya, kasaysayan, o sa agham pampolitika ang kinikilala bilang tunay na eksperto at dalubhasa ng kani-kanilang mga kapwa sosyolohista, historyador, siyantistang politikal. Kaya ayon kay Bourdieu, isang uri ng simbolikong dahas ang pakikialam ng telebisyon sa pagkilatis ng mga personalidad sa loob ng mga disiplina.

\section{Ang Teorya ng mga Kapital}

Ipinaliwanag ni Bourdieu ang pagkakaiba-iba ng taglay na kapangyarihan ng mga indibidwal at insititusyon sa loob ng isang larangan, pati na ang pagkakaiba-iba ng mga habitus ng iba't ibang panlipunang uri at mas maliliit na pangkat, gamit ang kanyang teorya ng mga kapital. Isang uri ng kapangyarihan ang kapital na maaaring gamitin para makamtan ang mga kanais-nais na bagay o karagdagang kapangyarihan at iba pang anyo ng kapangyarihan. Ipinahayag niya: "Capital is accumulated labor ... which,

${ }^{15}$ Ibid., 29-30.

(c) 2014 F.P.A. Demeterio III and Leslie Anne L. Liwanag http://www.kritike.org/journal/issue 15/demeterio\&liwanag december2014.pdf

ISSN 1908-7330 
when appropriated on a private ... basis by agents or groups of agents, enables them to appropriate social energy in the form of reified or living labor."16 Ang kapangyarihan bilang kapangyarihan ay hindi maituturing na kapital kapag hindi ito ginagamit bilang kasangkapan para makamtan ang mga kanais-nais na bagay, o hindi kaya para lumikha ng karagdagang kapangyarihan at iba pang anyo ng kapangyarihan. Naipakita na ni Marx kung gaano kasentro ang kapital sa kanyang pananaliksik tungkol sa modernong lipunan. Ngunit nakatali ang kapital na ito sa diskursong pinansiyal at pang-ekonomiko. Kaya para kay Marx, ang kapital ay pera o kayamanan na ginagamit sa paglikha ng karagdagang pera o kayamanan.

Sinusugan ni Bourdieu ang ideya ni Marx tungkol sa sentral na kahalagahan ng kapital, habang pinalawak ng Pranses na pantas ang para sa kanya ay makitid na pagdalumat ng Alemang pilosopo sa konsepto ng kapital. Sinabi niya: "It is in fact impossible to account for the structure and functioning of the social world unless one reintroduces capital in all its forms and not solely in the one form recognized by economic theory." 17 Kung para kay Marx ang kapital ay pera at kayamanang pinansiyal at pang-ekonomiko lamang, naniniwala si Bourdieu na may apat na pangunahing uri ang kapital: 1) ang pang-ekonomikong kapital na lubusan nang pinag-aralan ni Marx, 2) ang kultural na kapital, 3) ang panlipunang kapital, at 4) ang simbolikong kapital. Ang katanungan kung paano nagkakaiba-iba ang mga habitus ng mga indibidwal, mga institusyon, mga panlipunang uri, at malilit na pangkat ay ganap nang ipinaliwanag ni Bourdieu sa pamamagitan ng pagbibigay-diin sa katotohanang ang mga ito ay may taglay na iba't ibang kombinasyon ng pagkakaroon, hindi pagkakaroon at dami ng apat na uri ng kapital.

Katulad ng nabanggit na, ang pang-ekonomikong kapital ni Bourdieu ay katumbas sa kapital na tinatalakay ni Marx. Tumutukoy ito sa kayaman, pera, lupain, stock at share ng mga korporasyon, at iba pang mga kahalintulad na bagay.

Ang sinomang mayroong pang-ekonomikong kapital ay mayroon ding kapangyarihan sa loob ng isang larangan - ito ang dahilan kung bakit makapangyarihan ang mayayaman. Subalit, napansin ni Bourdieu na kahit sa mga simpleng lipunan, hindi lamang nakabatay ang kapangyarihan ng isang indibidwal sa kanyang lupain, alagang hayop, at mga kagamitan sa pagsasaka. Nakabase rin ito sa laki ng kanyang angkan na maaari niyang sandalan tuwing magkakaroon ng problema. Gayundin sa lawak ng kanyang mga kaalyansa na maaari niyang maging kaabay sa palitan ng mga produkto, pangangalakal, at pakikidigma. Kaya malinaw para sa kanya na hindi sapat

\footnotetext{
16 Pierre Bourdeiu, "Forms of Capital," in J. Richardson ed., Handbook of Theory and Research in for the Sociology of Education (Westport, Connecticut: Greenwood, 1986), 46.

${ }^{17} \mathrm{Ibid}$.

(c) 2014 F.P.A. Demeterio III and Leslie Anne L. Liwanag http://www.kritike.org/journal/issue 15/demeterio\&liwanag december2014.pdf ISSN 1908-7330

(cc) BY-NC
} 
ang pang-ekonomikong kapital para ipaliwanag ang kabuoan ng kapangyarihan.

Marahil ang kultural na kapital ang pinakakilalang konsepto ni Bourdieu at ang pinakamadalas ding hinihiram ng mga mananaliksik sa larangan ng araling kultural. Tumutukoy ang kultural na kapital sa kaalamang propesyonal, kasanayang teknikal, edukasyon, katatasan sa pagsasalita, kaalaman tungkol sa sining at kultura, at panlasang astetikal. Sa isang modernong lipunan, nagiging kapital ang mga kultural na kasanayang ito dahil may aktuwal na merkado kung saan maaari ikalakal ang mga ito. Bilang halimbawa ng kultural na kapital ay ang diploma, masasabing nakikilala lamang ito bilang isang anyo ng kapangyarihan sa mga lipunan kung saan pinapahalagahan ang mga indibidwal na nakapagtapos sa kolehiyo. Sa kabilang banda, doon sa mga mas simpleng lipunan kung saan walang paki-alam ang mga mamamayan sa pormal na edukasyon, walang saysay at bisa ang isang diploma kahit pa magmumula ito sa mga pinakamahusay na unibersidad sa mundo.

Ipinaliwanag ni Bourdieu na matatagpuan sa tatlong anyo ang kultural na kapital. Una, bilang bahagi ng habitus, umiikot ito sa mga kasanayan at kaalaman sa pagkilos, pagdama, at pag-iisip na naisaloob na ng isang indibidwal. ${ }^{18}$ Edukado at kulturado ang tawag sa indibidwal na dumaan sa mahabang proseso ng pagkatuto na nag-umpisa pa noong kanyang kamusmusan. Ito ang dahilan kung bakit hindi maaaring bigla ring maging edukado at kulturado ang isang indibidwal na biglang yumaman. Kahit anomang gawin niyang pagkukunwaring edukado at kulturado, mahahalata at mahahalata ang kanyang kakulangan sa kultural na kapital. Mahalaga para kay Bourdieu ang proseso ng pagpapalaki ng mga magulang sa kanilang mga anak dahil dito isinasalin ng isang henerasyon ang kanilang kultural na kapital patungo sa susunod na henerasyon. ${ }^{19}$

Pangalawa, maaari ring matagpuan sa obhektipikadong anyo ang kultural na kapital. Tumutukoy ito sa mga materyal na kagamitan tulad ng mga libro, likhang sining, at instrumentong pang-agham na nangangailangan ng mataas na antas ng kaalaman at kasanayan para magamit at pakinabangan. ${ }^{20}$ Kadalasang mas madaling dayain ang obhektipikadong anyo ng kultural na kapital kaysa sa naisaloob nang anyo nito. Halimbawa, mababatid na madaling paligiran ng isang indibidwal na biglang yumaman ang kanyang sarili ng mga libro, likhang sining at instrumentong pangagham. Gayunpaman, sa oras na tanungin siya tungkol sa mga katangian at saysay ng mga bagay na ito, lalantad din ang kanyang kakulangan sa naisaloob nang kultural na kapital.

\footnotetext{
18 See ibid., 47.

${ }^{19}$ See ibid., 48.

${ }^{20}$ See ibid., 47.
} 


\section{ANG PILOSOPIYA NI PIERRE BOURDIEU}

Pangatlo, maari ring matagpuan sa institusyonal na anyo ang kultural naapital. Tumutukoy ito sa laganap na halaga sa paggagawad ng diploma sa loob ng modernong sistema ng edukasyon..$^{21}$ Kapansin-pansin sa modernong lipunan na madalas binibigyan ng bigat ang diploma kaysa aktuwal na kaalaman at kasanayan ng mga indibidwal. Ito ang dahilan kung bakit sa institusyonal na anyo ng kultural na kapital ibinubuhos ng mga kasapi ng mataas at gitnang panlipunang uri ang kani-kanilang pangekonomikong kapital para masalinan ng sapat na kultural na kapital ang kani-kanilang mga anak. May institusyonal na batayan ang ganitong anyo ng kultural na kapital, kaya mas mapagkatiwalaan ito kaysa tiyagaan at swertihan na pagsasalin ng internalisadong kultural na kapital. Ibig sabihin, kapag may sapat na yaman ang mga magulang, habang may sapat na talino at tiyaga naman ang kanilang mga anak, may malaking tiyansa ang mga ito na magawaran ng institusyonal na kultural na kapital matapos ang ilang taong pormal na pag-aaral.

Nabanggit na ng papel na ito na kahit sa isang simpleng lipunan, hindi lamang nakabatay sa lupain, alagang hayop, at kagamitan sa pagsasaka ang kapangyarihan ng isang pamilya, kundi pati na sa laki ng angkan at lawak ng mga ka-alyansa nito.

Ang mga ito ang ilan sa mga anyo ng panlipunang kapital, ang pangatlong uri ng kapital ayon kay Bourdieu. Ipinaliwanag niya:

Social capital is the aggregate of the actual or potential resources which are linked to possession of a durable network of more or less institutionalized relationships of mutual acquaintance and recognition-or in other words, to membership in a group - which provides each of its members with the backing of the collectivelyowned capital, a 'credential' which entitles them to credit, in the various senses of the word..$^{22}$

Tungkol sa mga kakilala, ka-sosyo, kamag-anak, at ka-alyansa na maaaring pagmumulan ng tulong, palitan, kalakal, proteksiyon, rekomendasyon, at iba pang kahalintulad na bagay ang panlipunang kapital. Koneksyon ang dala ng panlipunang kapital. Paniguradong makapangyarihan ang sinomang sagana sa ganitong anyo ng kapital dahil mayroon siyang mas malawak na merkado kung saan maaari niyang ialok ang kanyang ibang kapital. Mas mahirap isalin mula sa isang henerasyon patungo sa susunod na henerasyon ang panlipunang kapital kumpara sa

$$
\begin{aligned}
& { }^{21} \text { See ibid. } \\
& { }^{22} \text { Ibid., } 51 .
\end{aligned}
$$

(c) 2014 F.P.A. Demeterio III and Leslie Anne L. Liwanag http://www.kritike.org/journal/issue 15/demeterio\&liwanag december2014.pdf ISSN 1908-7330 
pang-ekonomiko at kultural na mga kapital. Hindi sapat para sa isang indibidwal ang pagkakaroon ng mga magulang na may malawak na panlipunang kapital. Kung may mamanahin man siyang ilang koneksyon, dapat mayroon pa rin siyang sariling kasanayan sa pagpapanatili at pagpapalawak ng mga ito. ${ }^{23}$

Ang simbolikong kapital ang pang-apat na uri ng kapital ayon kay Bourdieu. Tumutukoy sa karangalan at di-pormal na kapangyarihang politikal. May ilang indibidwal sa loob ng lipunan na kahit walang hinahawakang posisyon, tinitingala at kinikilala bilang lider. Kaya sinusunod ng iba ang sinomang mayroong simbolikong kapital. Isinulat niya: "Symbolic capital is credit, it is the power granted to those who have obtained sufficient recognition to be in position to impose recognition." 24 Isang matingkad na halimbawa ng mga indibidwal na may taglay na simbolikong kapital sa konteksto ng Pilipinas ang mga artista sa pelikula at telebisyon. Makikitang pinaniniwalaan sila ng masa sa oras na mag-endorso ng mga kandidato sa politika o hindi kaya tumakbo sila bilang mga kandidato mismo.

Naniniwala si Bourdieu na maaaring magpalit-palit ng uri ang apat na kapital. Ibig sabihin, ang pang-ekonomikong kapital ay maaaring gawing kultural, o panlipunan, o simbolikong kapital; kagaya na ang kultural na kapital ay maaaring gawing pang-ekonomiko, o panlipunan, o simbolikong kapital; o kaya ang panlipunang kapital ay maaaring gawing pangekonomiko, o kultural, o simbolikong; at pati rin ang simbolikong kapital ay maaaring gawing pang-ekonomiko, o kultural, o panlipunang capital. ${ }^{25}$

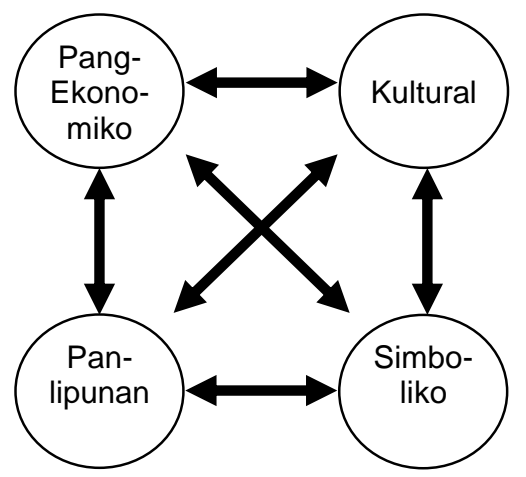

Figure 2: Ang Posibilidad sa Pagpapalit-Palit-Uri ng Apat na Kapital

Isang halimbawa ng pagpapalit-uri ng pang-ekonomikong kapital patungong kultural na kapital ang mga magulang na nagbubuhos ng

${ }^{23}$ See ibid., 51-52.

24 Pierre Bourdieu, In Other Words: Essays Towards a Reflexive Sociology, trans. by Loic Wacquant \& Matthew Lawson (Stanford, California: Stanford University Press, 1990), 138.

${ }^{25}$ See Figure 2.

(C) 2014 F.P.A. Demeterio III and Leslie Anne L. Liwanag http://www.kritike.org/journal/issue 15/demeterio\&liwanag december2014.pdf

ISSN 1908-7330 


\section{ANG PILOSOPIYA NI PIERRE BOURDIEU}

kayamanan para sa pagpapaaral ng kanyang anak. Isa namang halimbawa ng pagpapalit-uri ng kultural na kapital patungong pang-ekonomikong kapital ang isang bagong gradwado mula sa isang unibersidad na nakakuha ng magandang trabaho. Ang isang negosyante na nakikinabang sa kanyang pagkakaroon ng maraming kakilala para makapagbenta ng kanyang produkto ay isa namang halimbawa ng pagpapalit-uri ng panlipunang kapital pantungong pang-ekonomikong kapital. Ang isang respetadong indibidwal na nakikiusap sa kanyang mga tagahanga at tagasunod na suportahan ang kanyang pagtakbo bilang kandidato ay isa namang halimbawa ng pagpapalit-uri ng simbolikong kapital patungong panlipunang kapital.

Kahit lumihis si Bourdieu sa kaisipan ni Marx tungkol sa bilang ng mga kapital, sinang-ayunan pa rin niya ang Alemang Pilosopo tungkol sa kahalagahan ng pang-ekonomikong kapital. Nilinaw niya:

So it has to be posited simultaneously that economic capital is at the root of all the other types of capital and that these transformed, disguised forms of economic capital, never entirely reducible to that definition, produce their most specific effects only to the extent that they conceal ... the fact that economic capital is at their root, in other words ... at the root of their effects. ${ }^{26}$

Dagdag dito, ipinaliwanag ni Bourdieu na kahit maaaring magpapalit-palit-uri ang kanyang apat na kapital, ang pang-ekonomikong kapital pa rin ang pinakamabilis at pinakamadaling makapagpalit-uri. ${ }^{27}$

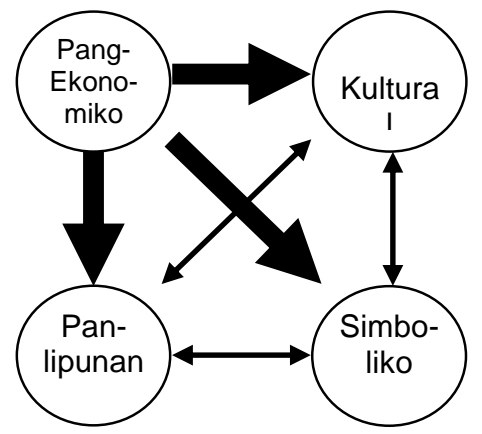

Figure 3: Ang Bentahe ng Pang-Ekonomikong Kapital sa Pagpapalit-Palit ng Uri

Madalas, kahit gaano kadami o kabigat ang kultural, panlipunan, at simbolikong kapital ang hawak ng isang indibidwal, mahirap pa rin itong

${ }^{26}$ Bourdieu, "Forms of Capital," 54.

27 See Figure 3.

(c) 2014 F.P.A. Demeterio III and Leslie Anne L. Liwanag http://www.kritike.org/journal/issue 15/demeterio\&liwanag december2014.pdf ISSN 1908-7330 
ipagpalit-uri patungong pang-ekonomikong kapital. Kaya malaki ang lamang ng isang indibidwal na may marami o mabigat na pangekonomikong kapital.

\section{Ilang Aplikasyon ng Teorya ng mga Kapital sa Araling Kultural}

Sisiyasatin ng seksiyong ito kung paano ginamit ni Bourdieu ang kanyang teorya ng mga kapital sa kanyang pananaliksik tungkol sa estetika, edukasyon, at panlipunang reproduksyon.

Estetika at mga Kapital: Nakabatay sa mga konsepto ng pangekonomiko at kultural na kapital ang pananaliksik ni Bourdieu tungkol sa estetikang Pranses. Naniniwala siya na kung ang kultural na pagkakaiba ng mga panlipunang uri sa loob ng moderno at industriyalisadong lipunan ang pag-uusapan, pinakamahalaga ang dalawang nabanggit na kapital. Kaya gamit ang mga ito, nirebisa niya ang simplistiko at tradisyonal na klasipikasyon ng mga panlipunang uri na binubuo lamang ng naghahari, gitna, at mababang uri. Naniniwala siya na ang ganitong ka-payak na klasipikasyon ay hahantong sa pag-o-overlap ng mga katangiang kultural ng iba't ibang panlipunang uri. Malinaw para sa kanya na ang pagkakaiba-iba ng kultura ng mga panlipunang uri ay nakaugat sa pagkakaiba-iba ng parehong pang-ekonomikong kapital at kultural na kapital. Sa katunayan, tinawag niyang "dominanteng prinsipyo ng hirarkiya" ang pangekonomikong kapital, habang ang kultural na kapital bilang "sekondaryong prinsipyo ng hirarkiya." 28

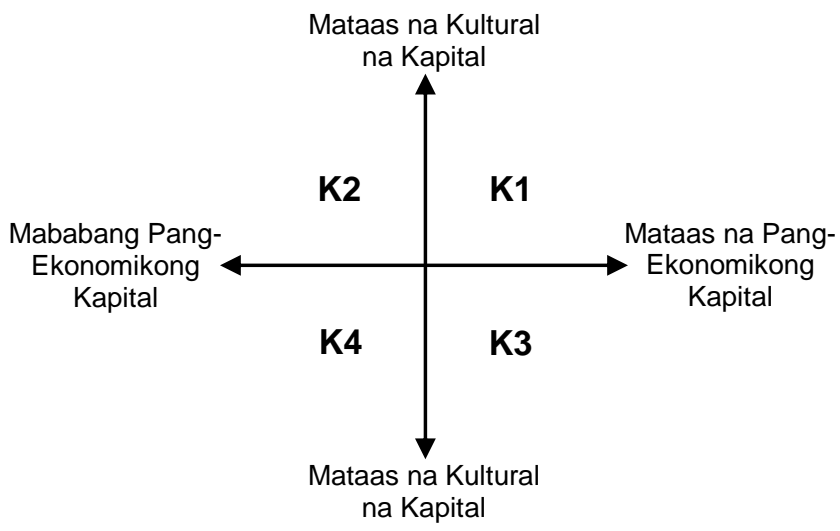

Figure 4: Alternatibong Konseptuwalisasyon ni Bourdieu tungkol sa mga Panlipunang Uri

Inilahad ni Bourdieu ang kanyang alternatibong konseptuwalisasyon ng mga panlipunang uri sa pamamagitan ng pagbuo ng

${ }^{28}$ See Pierre Bourdieu, La Noblesse d'État: Grandes Ecoles et Esprit de Corps (Paris: Editions de Minuit, 1989), 373-385.

(C) 2014 F.P.A. Demeterio III and Leslie Anne L. Liwanag http://www.kritike.org/journal/issue 15/demeterio\&liwanag december2014.pdf

ISSN 1908-7330 


\section{ANG PILOSOPIYA NI PIERRE BOURDIEU}

isang iskemang may dalawang dimensiyon, kung saan ginamit niya ang pang-ekonomikong kapital bilang $\mathrm{x}$ axis at kultural na kapital bilang y axis. ${ }^{29}$

Sa halip sa tatlong simplistiko at tradisyonal na panglipunang uri, iminungkahi niya ang apat na panlipunang pangkat na nagkakaiba sa taglay nilang pang-ekonomiko at kultural na kapital. ${ }^{30}$ Ang mga nasa unang kuwadra (K1) ay may matataas na pang-ekonomiko at kultural na kapital. Kasapi sila sa mga angkang dati nang mayaman at bahagi sila sa mga naghaharing uri. Ang mga nasa pangalawang kuwadra (K2) ay may mabababang pang-ekonomikong kapital ngunit mataas na kultural na kapital. Sila ay mga propesyonal, guro, at alagad ng sining. Kahit hindi sila mayaman bahagi pa rin sila ng mga naghaharing uri dahil nililikha at pinapanatili nila ang naghaharing kultura. Ang mga nasa pangatlong kuwadra (K3) ay may matataas na pang-ekonomikong kapital ngunit mababang kultural na kapital. Sila ang mga bagong usbong na mayayaman at mga negosyanteng sadyang may mababang kultural na kapital. Hawak nila ang kapangyarihang ekonomikal at kasapi rin sila sa mga naghaharing uri. Ang mga nasa pang-apat na kuwadra (K4) ay may mabababang pangekonomiko at kultural na kapital. Sila ay binubuo ng mahihirap at walang pinag-aralang masa, sila ang bumubuo ng mababang uri.

May tatlong puntos na dapat isaalang-alang ng mambabasa para maiiwasan ang impresyon na simplistiko rin ang alternatibong inilatag ni Bourdieu. Una, ang Figure 1 ay isang matematikong $\mathrm{x}$ at $\mathrm{y}$ graph na nangangahulugang ang bawat indibidwal ay may kanyang sariling puwesto batay sa dami at bigat ng kanyang pang-ekonomiko at kultural na mga kapital. Sa madaling salita, maski na sa loob ng isang kuwadra, mayroon din pagkakaiba sa mga puwesto at kapangyarihan ng mga saklaw na indibidwal o mas maliit na pangkat ng mga indibidwal. Pangalawa, magkakadikit-dikit at halos magkakarugtong na ang mga puwesto ng mga indibidwal at mas maliit na pangkat. Ang ibig sabihin, ang konsepto ng mga panlipunang uri ay mga konstrak lamang. Sa totoong buhay ay imposibleng tukuyin ang kanikanilang mga hangganan at pagitan. Pangatlo, ang $\mathrm{x}$ at $\mathrm{y}$ graph na may dalawa nang nabanggit na dimensiyon ay may pangatlo pang dimensiyon: ang dimension ng panahon. Kung titignan, isinaalang-alang ni Bourdieu ang katotohanang ang mga puwesto ng mga indibidwal at maliit na pangkat sa naturang graph ay gumagalaw habang lumilipas ang panahon. Lalong lilinaw ang pangatlong dimensiyon ng kanyang alternatibong konseptwalisasyon sa mga panlipunang uri kapag tatalakayin na ng seksiyon na ito ang kanyang pananaw tungkol sa panlipunang reproduksyon.

${ }^{29}$ See ibid., 383; see Figure 4.

${ }^{30}$ See Figure 4.

(c) 2014 F.P.A. Demeterio III and Leslie Anne L. Liwanag http://www.kritike.org/journal/issue 15/demeterio\&liwanag december2014.pdf ISSN 1908-7330

(cc) $\mathrm{BY}-\mathrm{NC}$ 
Sa pananaw ni Bourdieu, naaayon sa kinabibilangang kuwadra ng isang indibidwal ang estetika at panlasa para sa sining, musika, moda, babasahin, muwebles, at pagkain. Sinabi niya: "The spaces defined by preferences in food, clothing or cosmetics are organized according to the same fundamental structure, that of the social space determined by volume and composition of capital." 31 Para sa mga naroroon sa unang kuwadra na may panggastos at kakayahang umunawa sa sining at kultura, kinukunsumo nila ang mga produktong kultural na may kalidad at kamahalan. ${ }^{32}$ Habang para sa mga naroroon sa ikalawang kuwadra na walang sapat na panggastos ngunit may kakayahan sanang umunawa sa sining at kultura, kinukunsumo nila ang produktong kultural na may kalidad ngunit hindi kamahalan. ${ }^{33}$ Kung ang mga naroroon sa unang kuwadra ay kayang manood ng opera, ballet, at mamahaling konsiyerto, ang mga naroroon sa pangalawang kuwadra ay masaya na sa panonood ng art film, pagdalaw sa mga museo, at pagbabasa ng mabibigat na panitikan. Kung gourmet ang kinakain ng mga naroroon sa unang kuwadra, exotic at hindi pangkaraniwang pagkain na hindi kamahalan ang gustong kainin ng mga naroroon sa pangalawang kuwadra. Ang pagkakaiba sa estetika at panlasa ng mga naroroon sa una at pangalawang kuwadra ay nakabatay sa pagkakaiba sa kanilang pangekonomikong kapital. Kahit pareho silang may kakayahang umunawa sa sining at kultura, magkakaiba ang kani-kanilang pinipiling produktong kultural.

Para sa mga naroroon sa pangatlong kuwadra na may panggastos sana ngunit wala namang kakayahang umunawa sa sining at kultura, ang iba sa kanila ay walang paki-alam sa estetika at panlasa. Ang iba naman ay nagkukunwaring kulturado na madalas nagtutulak sa kanila sa pamimili ng mga mamahalin ngunit walang kalidad na produktong kultural. Habang para sa mga naroroon sa pang-apat na kuwadra na walang panggastos at wala ring kakayahang umunawa sa sining at kultura, ang kanilang estetika ay functional at abot-kaya. ${ }^{34}$ Kung gourmet ang kinakain ng mga naroroon sa unang kuwadra; exotic ang sa mga naroroon sa pangalawang kuwadra; at kung ano-ano lamang ang sa mga naroroon sa pangatlong kuwadra; ang kinakain ng mga naroroon sa pang-apat na kuwadra ay iyong maramihan, matataba, maaalat, at tipong nakakabusog. Kapag moda naman ang paguusapan, kung magagara at mamahalin ang isinusuot ng mga naroroon sa unang kuwadra; desente, maporma, ngunit hindi kamahalan ang sa mga naroroon sa pangalawang kuwadra; at samu't saring mamahaling pananamit

${ }^{31}$ Pierre Bourdieu, Distinction: a Social Critique of the Judgement of Taste, trans. by Richard Nice (Cambridge, Massachusetts: Harvard University Press, 1984), 208.

32 See ibid., 55-56.

${ }^{33}$ See ibid., 331.

${ }^{34}$ See ibid., 376.

(C) 2014 F.P.A. Demeterio III and Leslie Anne L. Liwanag http://www.kritike.org/journal/issue 15/demeterio\&liwanag december2014.pdf ISSN 1908-7330 


\section{ANG PILOSOPIYA NI PIERRE BOURDIEU}

ang mga naroroon sa pangatlong kuwadra; madalas walang paki-alam sa moda ang mga naroroon sa pang-apat na kuwadra.

Para kay Bourdieu, ang pagkakaiba-iba sa hawak na pangekonomiko at kultural na kapital ng mga kuwadra ay nagreresulta sa pagkakaiba-iba ng kani-kanilang estetika at panlasa. Ma-estetiko at malayaw ang estilo ng mga naroroon sa unang kuwadra, asetiko ang mga naroroon sa pangalawang kuwadra, mapagkunwari ang mga naroroon sa pangatlong kuwadra, at walang pakialam at praktikal ang mga naroroon sa pang-apat na kuwadra. Maaaring ituring ang estilo ng mga naroroon sa una at pangalawang kuwadra bilang mataas na kultura, o high/elite culture, at ang mga naroroon sa pangatlo at pang-apat na kuwadra bilang kulturang popular. Gayunman, alinsunod sa konseptwalisasyon ni Bourdieu, sa loob mismo ng mataas na kultura at pati na sa loob mismo ng kulturang popular, may pagkakaiba pa rin sa estilo bunsod sa pagkakaiba sa pang-ekonomikong kapangyarihan ng mga naroroon sa una, pangalawang kuwadra, at mga naroroon sa pangatlo at pang-apat na kuwadra.

Edukasyon at mga Kapital: Sa sub-seksiyong ito, susuriin ng papel ang isa pang aplikasyon ng teorya ng mga kapital ni Bourdieu na may kinalaman sa kanyang pagbatikos sa sistema ng edukasyon sa Pransiya. Ipinakita ni Bourdieu na kahit sa mga maunlad na bansa tulad ng Pransiya, na halos magkakapantay-pantay ang kalidad ng pampubliko at pampribadong paaralan, hindi pa rin magkakapantay-pantay ang oportunidad ng kabataan. Paniwala ni Bourdieu, dehado ang mga batang nanggagaling sa mga angkang may mababang kultural na kapital lalo na iyong mga nanggagaling sa pang-apat na kuwadra. Inilatag ni Bourdieu ang dalawang dahilan kung bakit nagkakaganito.

Tungkol ang unang dahilan sa pangarap at ekspektasyon. Ang mga batang nanggagaling sa mabababang uri ng lipunan ay kadalasan walang matayog na realistikong pangarap, habang ang kani-kanilang pamilya naman ay wala ring mataas na ekspektasyon para sa kanila. ${ }^{35}$ Kahit ipamudmod man sa kanila ng pamahalaan ang libreng tersiyaryong edukasyon, hindi rin kakagat sa ganitong oportunidad o magpursigeng magtapos ang karamihan sa kanila. Samantalang may mataas na pangarap sa buhay na sinasabayan ng mataas ding ekspektasyon mula sa kani-kanilang mga pamilya ang mga batang nanggagaling sa matataas na uri ng lipunan. Ipinakita ni Bourdieu na may taglay na disposisyon ang mga naghaharing pamilya para sa edukasyon na nangangahulugang "propensity to consent to the investment in time, effort and money necessary to conserve and to increase cultural capital." ${ }^{36}$ Ang kabataan nila ay halos itinutulak na patungo

${ }^{35}$ See Pierre Bourdieu, "Cultural Reproduction and Social Reproduction," in J. Karabel \& A. H. Halsey eds., Power and Ideology in Education (Oxford: Oxford University Press, 1977), 495. ${ }^{36} \mathrm{Ibid} ., 495$.

(c) 2014 F.P.A. Demeterio III and Leslie Anne L. Liwanag http://www.kritike.org/journal/issue 15/demeterio\&liwanag december2014.pdf ISSN 1908-7330

(cc) BY-NC 
sa pamantasan at minamanmanan para magtapos ng kani-kanilang binabalak na degri. Ayon kay Bourdieu, magkakaiba ang tingin ng mga panlipunang uri sa edukasyon. Kung para sa mga kasapi ng mabababang uri, isa itong hindi pangkaraniwang pagkakataon na para lamang sa kanilang talagang matalinong kabataan; para sa mga kasapi ng matataas na uri, kailangangkailangan ng kanilang kabataan ang edukasyon.

Tungkol sa ekspekstasyon ng mga guro at paaralan ang ikalawang dahilan ni Bourdieu. Pinuna niya ang hindi malay na pagkiling ng mga gurong pabor sa kabataang may namanang mataas ng kultural na kapital mula sa kani-kanilang tahanan. Isinulat ni Bourdieu:

By doing away with giving explicitly to everyone what it implicitly demands of everyone, the educationa system demands of everyone alike that they have what it does not give. This consists mainly of linguistic and cultural competence and that relationship of familiarity with culture which can only be produced by family upbringing when it transmits the dominant culture. ${ }^{37}$

Kung susuriin, mas madali ang pag-aaral para sa kabataang may hawak na mataas na kultural na kapital kaysa kabataang mababa lamang ang hawak na kultural na kapital. Sa kalaunan, ang nakalalamang na kabataang ay tuloy-tuloy sa pag-akyat sa pataas nang pataas na mga antas ng edukasyon, habang tila gumagapang, hirap na hirap, at madalas tumitigil na lamang sa pag-aaral ang nalalamangang kabataan.

Ipinakita ni Bourdieu na ang kakulangan sa edukasyonal na tagumpay ng mga kasapi ng mabababang uri ang isang problemang hindi matutugunan sa pamamagitan ng mga iskolarship. Hindi lamang ito nakaugat sa kakulangan sa pang-ekonomikong kapital, kundi kakulangan lalo na sa kultural na kapital. Bunsod nito, sa halip na magbigay ng panlipunang mobilidad ang edukasyon, may lihim itong hegemonya para mapanatili ang kasalukuyang kaayusan. Binigyang diin niya:

(Education) is in fact one of the most effective means of perpetuating the existing social pattern, as it both provides an apparent justification for social inequalities and gives recognition to the cultural heritage, that is, to a social gift treated as a natural one. ${ }^{38}$

${ }^{37}$ Ibid., 494

${ }^{38}$ Pierre Bourdieu, "The School as a Conservative Force: Scholastic and Cultural Inequalities," in J. Eggleston ed., Contemporary Research in the Sociology of Education (London: Methuen, 1974), 32.

(C) 2014 F.P.A. Demeterio III and Leslie Anne L. Liwanag http://www.kritike.org/journal/issue 15/demeterio\&liwanag december2014.pdf ISSN 1908-7330 
Panlipunang Reproduksyon at mga Kapital: Sa sub-seksiyong ito, susuriin ng papel ang isa pang aplikasyon ng teorya ng mga kapital ni Bourdieu na may kinalaman sa kanyang pananaliksik at pagbabatikos sa panlipunang reproduksyon. Ang mga indibidwal na naroroon sa iba't ibang kuwadra ay may kani-kanilang diskarte para maisalin ang kani-kanilang kapangyarihan at kayamanan sa kani-kanilang kabataan. ${ }^{39}$ Para sa mga naroroon sa unang kuwadra, ipinamana nila ang kanilang kayaman (pera, lupain, stocks at shares, negosyo, at kahalintulad na bagay) sa kanilang mga anak. ${ }^{40}$ Nabanggit na ng papel kung gaano kadali isalin ang pangekonomikong kapital sa lahat ng uri ng kapital. Bukod sa ipinamamanang pang-ekonomikong kapital, nagbubuhos din ng malaking halaga ang mga naroroon sa unang kuwadra para sa edukasyon ng kanilang kabataan. Kadalasan ang mga anak ng mga naroroon sa unang kuwadra ay nag-aaral sa mga primera-klaseng pamantasan. Mataas ang hawak na kultural na kapital ng kabataang nagmumula sa unang kuwadra, madalas na nagtatagumpay sila sa kanilang pag-aaral. Kung mapapanatili ng kabataang ito ang kanilang mataas na pang-ekonomikong kapital, mananatili silang naroroon sa unang kuwadra at magiging matagumpay ang proseso ng panlipunang reproduksyong hangad ng kanilang mga magulang.

Para sa mga naroroon sa pangalawang kuwadra, ang panlipunang reproduksyong hangad nila ay hindi tunay na panlipunang reproduksyon dahil pinangarap nilang tataas ang pang-ekonomikong kapital ng kanilang kabataan. ${ }^{41}$ Sa madaling sabi, gusto ng mga naroroon sa pangalawang kuwadra na mangingibang kuwadra ang kanilang kabataan patungo sa unang kuwadra. Kaya sa pamamagitan ng kanilang pagtutok sa edukasyon ng kanilang mga anak, sinisikap ng mga naroroon sa pangalawang kuwadra na magiging mas maginhawa ang pamumuhay ng kanilang kabataan pagdating ng panahon. Gawa ng mataas din ang hawak na kultural na kapital ng kabataang nagmumula sa pangalawang kuwadra, madalas matagumpay rin sila sa kanilang pag-aaral. Minsan nakakamtan ng kabataang ito ang mas mataas ng pang-ekonomikong kapital. Ngunit kadalasan nahihirapan pa rin silang lumipat sa unang kuwadra dahil wala naman silang namamanang substansyal na pang-ekonomikong kapital mula sa kanilang mga magulang. Kaya kahit hangad ng mga naroroon sa pangalawang kuwadrang pumanhik sa unang kuwadra ang kanilang kabataan, madalas sa ikalawang kuwadra pa rin mananatili ang mga ito. Bigo man ang reproduksyong gustong mangyari ng mga naroroon sa pangalawang kuwadra, matagumpay pa rin ang tunay na panlipunang reproduksyon.

\footnotetext{
${ }^{39}$ See Bourdieu, Disntinction, 125-168.

${ }^{40}$ See ibid., 121.

${ }^{41}$ See $i b i d$.
}

(c) 2014 F.P.A. Demeterio III and Leslie Anne L. Liwanag http://www.kritike.org/journal/issue 15/demeterio\&liwanag december2014.pdf ISSN 1908-7330

(cc) $\mathrm{BY}-\mathrm{NC}$ 
Para sa mga naroroon sa pangatlong kuwadra, katulad sa mga naroroon sa unang kuwadra, ipinamana rin nila ang kanilang kayamanan (pera, lupain, stocks at shares, negosyo, at kahalintulad na bagay) sa kanilang mga anak, at nagbubuhos din sila ng malaking halaga para sa edukasyon ng kanilang kabataan. ${ }^{42}$ Binigyang-diin ni Bourdieu: "Those fractions of the dominant class and middle class who are richest in economic capital ... have had to make greatly increased use of the educational system in order to ensure their social reproduction." 43 Kaya katulad ng mga naroroon sa pangalawang kuwadra, ang panlipunang reproduksyong hangad ng mga naroroon sa pangatlong kuwadra ay hindi rin tunay na panlipunang reproduksyon dahil pinangarap naman ng mga naroroon sa pangatlong kuwadra na tataas ang kultural na kapital ng kanilang kabataan at papanhik sila sa unang kuwadra. Pero, kahit naisin man ng mga naroroon sa pangatlong kuwadra na salinan ng mataas na kultural na kapital ang kanilang kabataan sa pamamagitan ng edukasyon, medyo mahihirapan ang kabataang ito dahil sa kanilang kakulangan sa namanang kultural na kapital mula sa kanilang tahanan. Subalit dahil sa katotohanang mas madaling magpalit-uri ang pang-ekonomikong kapital, mas madali rin para sa kabataang nagmumula sa pangatlong kuwadra na pumanhik sa unang kuwadra kaysa kabataang nagmumula sa pangalawang kuwadra. Mas madalas matagumpay ang reproduksyong gustong mangyari ng mga naroroon sa pangatlong kuwadra, kaya madalas bigo naman ang tunay na panlipunang reproduksyon.

Para sa mga naroroon sa pang-apat na kuwadra, ang kanilang diskarte at pakikipagsapalarang bumuti ang kinabukasan ng kanilang kabataan ay laging humahantong sa kanilang pagiging biktima. Bunsod ito sa kanilang kawalan ng pang-ekonomikong kapital na maaaring ipamana sana sa kanilang mga anak, sa kanilang kawalan ng kakayahan, at tiyagang magtiwala sa magandang kinabukasan na ipinangako ng edukasyon. Ang kanilang habitus na kapos sa kultural na kapital ang pumipigil sa kanilang magkaroon ng realistikong pangarap para sa mas maginhawang kinabukasan ng kanilang kabataan. Kaya ang kabataang nagmumula sa pang-apat na kuwadra ay sa pang-apat na kuwadra din hahantong, nagsumikap man o hindi ang kanilang mga magulang na mangibang kuwadra sila baling araw.

\section{Si Bourdieu bilang Pampublikong Intelektuwal}

Ang kaisipan ni Bourdieu tungkol sa pagiging isang pampublikong intelektuwal at kung paano niya ito isinasabuhay ang panghuling paksang

\footnotetext{
42 See ibid.
}

${ }^{43}$ Ibid., 133.

(C) 2014 F.P.A. Demeterio III and Leslie Anne L. Liwanag http://www.kritike.org/journal/issue 15/demeterio\&liwanag december2014.pdf 


\section{ANG PILOSOPIYA NI PIERRE BOURDIEU}

tatalakayin ng papel. May magkakasalungat na modelo ng pagiging intelektuwal na maaaring banggitin para maihayag ang kaisipan ni Bourdieu tungkol dito. Ito ang binaryo ng intelektuwal bilang isang tagakonserba o tagaturo ng kaalaman, at intelektuwal bilang tagasaliksik o tagalikha ng kaalaman. Kahit na parehong ginampanan ni Bourdieu bilang isang propesor ang binaryong ito, mas matimbang para sa kanya ang modelo ng intelektuwal na subsob sa pananaliksik at paglikha ng kaalaman. Gayunpaman, hindi nangangahulugang basta na lamang niyang iminungkahi na dapat mananaliksik at lilikha ng kaalaman ang isang intelektuwal. Hindi pumapabor si Bourdieu sa mga mananaliksik na mas nakatuon sa mga proyektong bayad ng gobyerno at mga kapitalista. Sa puntong ito, malinaw ang kanyang pagiging makakaliwa.

Sa usapin ng pagiging makakaliwang pampublikong intelektuwal, may dalawang modelo na maaaring banggitin para lalong maipaliwanag ang kaisipan ni Bourdieu tungkol dito. Ang dalawang modelong ito ay parehong tutol sa panghihimasok ng gobyerno at ng mga kapitalista sa proseso ng pananaliksik at paglilikha ng kaalaman. Una ang modelo ng organikong intelektuwal na dinalumat ni Gramsci. Isinasaad dito na dapat umusbong sa panig ng mga manggagawa at inaapi ang isang intelektuwal para maipagtanggol niya ang kanilang uri. Pangalawa ang modelo ng intelektuwal bilang kapwa-manlalakbay ng partidong komunista na dinalumat naman ni Sarte. Isinasaad dito na maaaring gumabay at bumatikos sa nasabi nang kaalyansa niyang partido ang isang intelektuwal bilang kapwa-manlalakbay.

Subalit, parehong hindi sinang-ayunan ni Bourdieu ang modelo nina Gramsci at Sartre. Kahit makakaliwa si Bourdieu, ayaw niyang mabahiran ng politika ang agham panlipunan. Tumututol siya hindi lamang sa panghihimasok ng gobyerno at mga kapitalista sa proseso ng pananaliksik, kundi pati na rin sa panghihimasok ng partido komunista at ng mga manggagawa at inaapi. Buo ang paniniwala niya na kung sakaling may agenda mang igigiit ang agham panlipunan, dapat manggagaling lamang sa loob ng agham panlipunan mismo at sa kanyang mga kaanib na intelektuwal. Ito ang dahilan kung bakit hindi nagustuhan ni Bourdieu ang modelo ng pampublikong intelektuwal na isinasabuhay ni Sartre, ang modelo ng isang unibersal na intelektuwal na nakikialam sa lahat ng usaping panlipunan kahit pa ang labas na sa kanyang espesyalisasyon.

Para kay Bourdieu, dapat nakatayo sa kanyang sariling kaalaman at may kabatiran ang pampublikong intelektuwal kung ano ang mga usaping nararapat niyang pakialaman at mga panig na nararapat niyang katigan at ipaglaban. Alinsunod dito, mas sinusunod ni Bourdieu ang modelo ng espesipikong intelektuwal na isinasabuhay ng Pranses na pilosopong si Michel Foucault (1926-1984). Sa umpisa, iniwasan ni Bourdieu ang pagharap

(C) 2014 F.P.A. Demeterio III and Leslie Anne L. Liwanag http://www.kritike.org/journal/issue 15/demeterio\&liwanag december2014.pdf ISSN 1908-7330

(cc) $\mathrm{BY}-\mathrm{NC}$ 
sa midya bilang pampublikong intelektwal. Ngunit sa bandang huling bahagi ng kanyang buhay noong kalagitnaan ng dekada nobenta, unti-unti niyang ginampanan ang naiwang papel ni Foucault bilang pangunahing pampublikong intelektuwal ng Pransiya.

\section{Mahahalagang Puntos sa Pilosopiya ni Bourdieu para sa mga Pag-aaral ng Teksto at Kultura ng Pilipinas}

Bilang pagtatapos, may ilang makukuhang mahahalagang puntos mula sa kaisipan ni Bourdieu na magagamit ng mga Pilipino sa pagpapayaman at pagpapayabong ng mga tekstuwal at kultural na proyekto, lalong-lalo na sa larangan ng araling Pilipino.

Mula sa mga nakaraang pagtatalakay, mababatid na napakainteresanteng gamitin ang konseptong larangan ni Bourdieu upang sipatin ang mga mikroskopikong tunggalian sa loob ng mga larangang matatagpuan sa pang-araw-araw na buhay bilang mga Pilipino at sa ibaibang dimensiyon at aspekto sa lipunan. Nagawa nang tignan ni Bourdieu ang larangang mas midya, edukasyon, at ilang propesyon. Subalit nakabatay lamang ang mga ito sa kanyang etnograpiya sa Pransiya. Mula rito, masasabing hindi isang duplikasyon kapag susuriin ang parehong mga larangan ayon sa etnograpiya ng sariling bansa sapagkat maliwanag na iba ang kulturang nananalaytay sa Pransiya kumpara sa iba pang bansa sa mundo tulad ng Pilipinas.

Bunsod ng reyalidad na magkakaiba ang mga kondisyon at sirkumstansiya ng Pransiya at Pilipinas, magkakaiba rin ang anyo at proseso ng tunggalian sa nabanggit nang mga larangan. Bukod sa mga larangang napag-aralan na ni Bourdieu, marami pang ibang larangang maaaring pagtutuunang pansin ang mga Pilipinong mananaliksik tulad ng relihiyon, halalan, social media, at iba pang mga kahalintulad na penomenon.

Makabuluhan din kung gagamitin ang konseptong simbolikong dahas ni Bourdieu para alamin ang partikular na anyo, bisa, at epekto nito sa loob ng mga larangang Pilipino. Katulad ng malaking posibilidad na may pagkakaiba sa anyo ng mga tunggalian sa loob ng mga larangang Pranses at ng mga larangang Pilipino, malaki rin ang posibilidad na may pagkakaiba sa anyo, bisa, at epekto ng mga simbolikong dahas na Pranses at Pilipino.

Maaaring gawing modelo ang pambabatikos ni Bourdieu sa banayad na sabwatan ng mga kapitalista, gobyerno, at dyornalismong pantelebisyon bilang modelo sa sariling pagsusuri sa mga bakas ng sabwatan na matatagpuan sa aktuwal na mga diskurso ng dyaryo, radyo, at telebisyon.

Maaaring makatulong ang pambabatikos ni Bourdieu sa simbolikong dahas na ipinapataw ng telebisyon sa mga tagapanood bilang modelo sa sariling pagsusuri sa lawak at lalim ng pagkontrol ng dyaryo,

(C) 2014 F.P.A. Demeterio III and Leslie Anne L. Liwanag

http://www.kritike.org/journal/issue 15/demeterio\&liwanag december2014.pdf

ISSN 1908-7330 


\section{ANG PILOSOPIYA NI PIERRE BOURDIEU}

radyo, at telebisyon sa publikong espasyo (public sphere). Ang kakulangan ng mga Pilipino sa pagbabasa ng mga seryosong literatura ang naglagay sa mga mamamayan sa mas mapanganib na sitwasyon dahil kapos ang bawat isa sa perspektibong maaaring gamitin para salain o di kaya labanan ang simbolikong dahas na inihain ng mas midya araw-araw.

Kung susuriin, masasabing maiuugnay at kapaki-pakinabang ang pag-aaral ni Bourdieu tungkol sa sistema ng edukasyon, teorya ng mga kapital at panlipunang reproduksyon para sipatin ang sariling sistema ng edukasyon sa bansa. Ano kaya ang pagkakapareho at pagkakaiba sa mga uri ng kapital na sangkot sa proseso ng edukasyon sa konteksto ng Pransiya at Pilipinas? Ano kaya ang pagkakapareho at pagkakaiba sa mga estratehiya ng pagpapalit-uri ng mga Pranses at ng mga Pilipino? Isang halimbawa ang pagpapalit-uri ng pang-ekonomikong kapital patungong kultural na kapital ng mga magulang na nagbubuhos ng kayamanan at salapi upang mapag-aral ang kanyang anak. Walang-duda na sa Pilipinas, isang malaking bagay ang mapagtapos sa pag-aaral ang anak dahil hindi lamang kultural na kapital ang ipinapamana ng mga magulang, bagkus maaaring maging bukal ang edukasyon sa pagpapayabong ng iba pang kapital o maaaring maibalik ang pang-ekonomiyang kapital na sandaling ginamit sa pagpapaaral ng anak.

Sa kabilang kamay, gamit ang mga kapital na kanyang ibinahagi, mas makikita ng mga Pilipino kung gaano ka-di-pantay-pantay ang pangako na inaalay ng edukasyon. Malayong-malayo ang kinabukasang ipinapangako ng isang pampubliko at ng isang pampribadong paaralan, at malayong-malayo pa rin ang kinabukasang ipinapangako ng isang karaniwang pampribado at ng isang primera-klaseng pampribadong paaralan. Sa umpisa pa lamang ay alam na natin na sa pagtatapos ng isang grupo ng kabataan ang kanilang oportunidad ay hindi magkakapantaypantay.

Kapag gagayahin ang pagdalumat ni Bourdieu sa apat na kuwadra sa konteksto ng Pilipinas, ano-ano kayang mga pangkat ng indibidwal at propesyon at panlipunang uri ang hahantong sa bawat kuwadrang ito? Anoano kaya ang mga espisipikong manipestayon ng kapangyarihan, panlasa, estetika at pananaw sa buhay ang taglay ng mga Pilipinong naroon sa bawat kuwadra? Gamit ang konseptuwalisasyong ito sa mga panlipunang uri ng Pilipinas, maraming aspekto at dimensiyon ng panlipunang tunggalian ang maaaring mas pulidong mahimay.

Interesanteng tignan ang kaisipan ni Bourdieu ukol sa pagiging isang pampublikong intelektwal kapag ikokonteksto sa Pilipinas. Naangkop kaya ang kanyang mga mungkahi kung paano dapat gagalaw ang isang pampublikong intelekwal sa mga sirkumstansya at reyalidad ng Pilipinas? Kung susuriin, ang kinikilalang pambansang bayaning si Jose P. Rizal, ang nangungunang pampublikong intelektwal sa bansa ay tila hindi papasa sa

(C) 2014 F.P.A. Demeterio III and Leslie Anne L. Liwanag http://www.kritike.org/journal/issue 15/demeterio\&liwanag december2014.pdf ISSN 1908-7330

(cc) $\mathrm{BY}-\mathrm{NC}$ 
pamantayan ni Bourdieu. Una, hindi tulad ng ilang pampublikong intelektwal sa dahon ng kasaysayan, hindi umusbong si Rizal kabilang ang mga manggagawa at inaapi. Katunayan, maykaya ang pamilya nila sapagkat binubuo sila ng mga negosyante at magsasaka na nangungupahan sa hasyenda ng mga prayleng Dominikano. Pangalawa, gayong pasok si Rizal sa aspektong pagkasubsob sa pananaliksik at paglikha ng mga bagong kaalaman, imposibleng hindi maaaring mabahiran ng politika ang kanyang pagiging pampublikong intelektwal sapagkat isa ring mukha ng politika ang kagustuhan niya mismong magkaroon ng ganap na pagkakaisa sa Pilipinas bilang nasyon at pagkakaroon ng kamalayan ng mga mamamayan sa mga panlipunang isyu upang makamit ang kalayaan. Dagdag dito, hindi rin magiging posible sa kaso ni Rizal na manatili na lamang sa loob ng larangang agham panlipunan mismo bilang social scientist at sa kanyang mga kaanib na intelektuwal. Ano pa man, binubuo ang lipunan ng mga manggagawa, inaapi, at naghaharing-uring imposibleng hindi maiangkla sa mga agendang iginigiit ng nasabing larangan. Sa kabilang banda, maipagmamalaking isa si Rizal sa mga mananaliksik na hindi nakatuon sa mga proyektong bayad ng gobyerno at mga kapitalista. Ang totoo pa niyan, kinikilala siyang walangtakot na repormistang isiniwalat ang pang-aabuso ng mga prayle sa mga Pilipino at mga katiwalian sa pamahalaan ng Kastila gamit ang kanyang mga panulat. May Pilipinong intelektwal kayang papasa sa pamantayan ni Bourdieu? Dapat bang isabuhay ng mga Pilipinong intelektwal ang mga pamantayang ito? Ilan lamang ito sa mga interesanteng katungan sa pakikipagdiyalogo sa kaisipan ni Bourdieu.

Mahalaga rin ang papel ng pagsusuri ni Bourdieu sapagkat hindi lamang masasarado sa kanyang mga mungkahing kapital ang kanyang naging pag-aaral. Mula sa mga nabanggit na, maaaring makatulong ang kanyang mga kapital bilang pundasyon upang magkaroon at makabuo ng iba pang kapital na maaaring gamitin upang maipamalas ang antas ng diskursong maiintindihan ng mga kapwa Pilipinong nasa larangan ng araling kultural at araling Pilipino.

Bilang pagtatapos, masasabing hindi lamang sa pang-ekonomikong kapital umiikot ang yaman ng isang tao. Nararapat na marunong din siyang gamitin ito upang magkaroon ng iba pang kapital katulad ng nabanggit na kanina. Gayunman, gayong lumihis si Bourdieu sa kaisipan ni Marx, walangdudang ang pagsasang-ayon niya kay Marx ukol sa kahalagahan ng pangekonomikong kapital dahil batid ng karamihan na sa apat na kapital, ito pa rin ang pinakamabilis at pinakamadaling makapagpalit-uri.

Department of Filipino, De La Salle University-Manila, Philippines

(c) 2014 F.P.A. Demeterio III and Leslie Anne L. Liwanag http://www.kritike.org/journal/issue 15/demeterio\&liwanag december2014.pdf 


\section{ANG PILOSOPIYA NI PIERRE BOURDIEU}

\section{References}

Bourdieu, Pierre and Loic Wacquant, An Invitation to Reflexive Sociology (Chicago: University of Chicago Press, 1992).

Bourdieu, Pierre, "Cultural Reproduction and Social Reproduction," in J. Karabel \& A. H. Halsey eds., Power and Ideology in Education (Oxford: Oxford University Press, 1977).

"Forms of Capital," in J. Richardson ed., Handbook of Theory and Research in for the Sociology of Education (Westport, Connecticut: Greenwood, 1986).

, "The School as a Conservative Force: Scholastic and Cultural Inequalities," in J. Eggleston ed., Contemporary Research in the Sociology of Education (London: Methuen, 1974).

Distinction: a Social Critique of the Judgement of Taste, trans. by Richard Nice (Cambridge, Massachusetts: Harvard University Press, 1984).

In Other Words: Essays Towards a Reflexive Sociology, trans. by Loic Wacquant \& Matthew Lawson (Stanford, California: Stanford University Press, 1990).

La Noblesse d'État: Grandes Ecoles et Esprit de Corps (Paris: Editions de Minuit, 1989).

, Language and Symbolic Power (Boston: Harvard University Press, 1991), 164.

On Television, trans. by Priscella Parkhurst (New York: The New Press, 1998), 15.

The Logic of Practice, trans. by Richard Nice (California: Stanford University Press, 1990).

(c) 2014 F.P.A. Demeterio III and Leslie Anne L. Liwanag http://www.kritike.org/journal/issue 15/demeterio\&liwanag december2014.pdf ISSN 1908-7330 